\title{
Cementless total hip arthroplasty in rheumatoid arthritis: a systematic review of the literature
}

\author{
Rob E. Zwartelé • Suzanne Witjes • \\ H. Cornelis Doets · Theo Stijnen · Rudolf G. Pöll
}

Received: 26 December 2010/Published online: 24 November 2011

(c) The Author(s) 2011. This article is published with open access at Springerlink.com

\begin{abstract}
Background Compromised rheumatic bone is a potential risk factor for mechanical complications in cementless total hip arthroplasty (THA) in cases of rheumatoid arthritis (RA). Increased rates of intra-operative fractures, component migration and (early) aseptic loosening are to be expected. Despite this, cementless THA is performed in cases of RA.

Methods A literature search on cementless THA in RA was performed in EMBASE (1993-2011), Medline (1966-2011) and the Cochrane Library. A systematic review was conducted with a special emphasis on mechanical complications. Results Twenty-three case series and five studies of implant registries were included. Acetabular fractures and/ or migration of the cup were reported in 9 out of 22 studies of the cup. Proximal femoral fractures and/or subsidence of the stem were reported in 14 out of 20 studies of the stem. Six studies compared failure rates of uncemented and cemented components due to aseptic loosening. The overall
\end{abstract}

R. E. Zwartelé ( $\square)$

Department of Orthopedic Surgery, Kennemer Gasthuis,

Haarlem, The Netherlands

e-mail: zwartele@kg.nl

R. E. Zwartelé · S. Witjes · H. C. Doets · R. G. Pöll Department of Orthopedic Surgery, Slotervaartziekenhuis, Amsterdam, The Netherlands

T. Stijnen

Department of Medical Statistics and Bioinformatics, Leiden University Medical Center, Leiden, The Netherlands

R. G. Pöll

Department of Orthopedic Surgery, Move Research Institute, VU University Medical Center, Amsterdam, The Netherlands failure rate ratio (uncemented/cemented) for the cup was 0.6 (95\% CI: 0.14-2.60) and for the stem 0.71 (95\% CI: $0.06-8.55)$, both favoring uncemented fixation. The failure rates in case series without a control group were compared to the NICE criteria (failure rate/1). The overall failure rate for the cup was 0.97 (95\% CI: 0.50-1.88) and for the stem 0.79 (95\% CI: $0.44-1.41$ ). Failure rates of aseptic loosening of higher than 1 (favoring cemented fixation) were reported in 6 out of 26 studies of the cup and in 2 out of 25 studies of the stem. In all these studies, the inferior implant designs were blamed, and not the type of fixation or the quality of the bone.

Conclusions Despite substantial rates of mechanical stem complications, no evidence was found to establish that cementless components perform less well than cemented components. The results justify the use of cementless THA in RA patients.

Keywords Rheumatoid arthritis - Total hip arthroplasty · Cementless · Uncemented · Review

\section{Introduction}

Rheumatoid arthritis (RA) strongly affects the properties of bone [1-3], while in addition bone metabolism is influenced by the intake of medication by RA patients $[4,5]$. The compromising biomechanical changes in rheumatic bone could increase the risk of mechanical complications in cementless implants, such as peri-prosthetic fractures, insufficient initial implant stability and insufficient osseous integration causing early implant failure.

This systematic literature review was conducted to investigate the results of uncemented total hip arthroplasty (THA) in RA patients, with a special emphasis on 
mechanical complications. The research questions formulated were: (1) What are the rates of early complications such as intra-operative, peri-prosthetic fractures, implant migration and early loosening? (2) What are the failure rates with aseptic loosening as end point compared to cemented implants in RA patients, or compared with the criteria of the National Institute of Clinical Excellence (NICE) [6]?

\section{Methods}

The systematic review was performed using methodology and checklists on search strategy, methods and results, according to the proposed methodology for systematic reviews of observational studies by the meta-analysis of observational studies in epidemiology (MOOSE) group [7].

\section{Search strategy}

A comprehensive search was performed on EMBASE (1993-2011), Medline (1966-2011) and the Cochrane Library. Search terms used were 'cementless OR uncemented AND hip arthroplasty AND RA'. The reference lists of each of the studies were manually inspected to find additional relevant studies.

Inclusion criteria were: (1) clinical studies on cementless THA in RA patients in comparison with cemented THA, and (2) clinical studies on cementless THA in RA patients with other than a cemented control group or no control group. Exclusion criteria were: (1) studies including revision cases, (2) studies containing previously published data, (3) studies without rheumatoid patients, (4) studies on other implants than conventional THA (e.g., resurfacing hip arthroplasty), (5) studies other than clinical studies such as reviews, radiological and retrieval studies, case reports and expert opinions.

To ensure that all relevant literature on cementless THA in RA patients was accounted for, and to minimize publication bias, there were no limitations on study quality, language of publication or year of publication.

\section{Data extraction}

Data were extracted by one of the investigators (first author) and checked for accuracy by a second investigator (second author). The information retrieved from each study included study design, sample size, patient characteristics, implants used, follow-up duration, definition of outcome measures and data analysis. The derived data included the incidence of intra-operative fractures and post-operative migration of components not defined as loose. The time from initial operation to revision was recorded. Early loosening was defined by the authors of the reports as aseptic loosening in an early phase following the initial operation. Failure events were described as any revision for aseptic loosening of cup or stem, or radiographical loosening as defined by the authors.

Quality appraisal in relation to research questions

To create a level of transparency in the quality of the studies, quality appraisal was performed on ten items selected out of previously described quality appraisal methods [8-11]. These were: (1) study design-whether the study design met the requirements of our research question, for example a comparative study with cemented THA as control group or a case series without control group; (2) prospective or retrospective study; (3) homogeneity concerning type of implant; (4) homogeneity concerning patient population-RA patients only or inclusion of patients with different types of inflammatory arthritis; (5) transparency of selection criteria for cementless THA; (6) transparency of outcome measures and assessment; (7) sample size, defined as years that hips were at risk of failure, calculated by multiplying the number of included hips by the years of follow-up, whereby 100 hip years was chosen as the arbitrary minimum; (8) transparency of missing data and loss to follow-up; (9) appropriate data management and statistics in relation to our research questions; (10) declaration of conflicts of interest.

The same investigators as mentioned earlier scored the items. Any disagreements were resolved by consensus. When no information was available for a potential bias, or if the method for addressing the bias was deemed inadequate, the item scored negative. An item scored positive when a serious attempt was made to minimize this risk of bias. A positive score did not mean that this potential bias was absent, nor did it imply that the techniques that were used to minimize bias were state of the art.

\section{Statistical methods}

To compare the results between the studies, failure was calculated as 'failure rate per 100 years of hips at risk'. 'Years of hips at risk' was calculated as number of hips in the study multiplied by the mean follow-up time. The failure rate was calculated per group (cementless/cemented) in comparative studies. In the absence of a control group in the case series, the NICE criteria (National Institute of Clinical Excellence) were used as a reference [6]. According to these criteria, survival at 10 years should be at least $90 \%$. Calculated as the failure rate per 100 'years of hips at risk', this represents one failure per 100 years. The confidence intervals for the failure rates of exactly $95 \%$ were based on the Poisson distribution. The 
random effects meta-analysis to obtain the overall failure rate of a number of case series was based on a random intercept Poisson model [12]. For the comparative studies, the groups were compared by calculating the failure rate ratio as the failure rate in the cementless group divided by the failure rate in the cemented group. The corresponding exact confidence intervals were based on the binominal distribution. The random effects meta-analysis to obtain the overall failure rate ratio of a number of comparative studies was based on the random intercept logistic regression model with offset variable, as described by Stijnen et al. [12]. The meta-analysis models were fitted using SAS NLMIXED version 9.2. All other analyses were carried out in STATA version 11.

\section{Results}

Search

Initially, 37 studies matched the search criteria. After close examination, nine of these were excluded: one article appeared to be a comment on another study [13], two studies included only juvenile chronic arthritis patients [14, 15], two studies contained revision cases [16, 17] and another two studies were on prostheses other than routinely used hip arthroplasties such as cementless polyethylene cups [18] and resurfacing prostheses [19]. Overlap of patient material was found in two other studies. In the study by Arnold et al. [20] and Schule et al. [21], the results of a prospective multicenter comparative study were published in two separate articles. For our analysis, their data were combined and the articles were treated as one study. In the study by Effenberger et al. [22] and Effenberger et al. [23], part of the patient material was used twice. Only the data from the first publication were used for the analysis.

The 28 included studies are listed in Table 1 together with the scores of the items used for quality appraisal. Three groups of studies were formed for both cup and stem separately: comparative studies (comparison between cementless and cemented components in RA), case series without control group, and registers (reports of national implant registers).

\section{Acetabular component outcome}

Acetabular fractures (Table 2): four studies reported acetabular fractures in 2-5\%. Three of these studies concerned perforations of the acetabular floor by threaded cups [20, $24,25]$, and the fourth study reported two acetabular rim fractures by a press-fit design [26]. All these fractures were treated conservatively, and none caused failure of the implant.

Migration (Table 2): six studies reported migrated cups, three of which reported rates of $10 \%$ or more [27-29].

Early loosening (Table 2): five studies reported early loosening. Dominkus et al. [27] reported three loose cups after an average period of 31 months. Zwartele et al. [25] reported that two cups were loosened within 2 years after implantation. The three other studies reported single cases of early loosening [26, 30, 31].

Aseptic loosening (Table 2; Figs. 1, 2): Table 2 shows the failure rates for aseptic loosening per 100 years of 'hips at risk'. Six studies reported failure rates higher than one (the NICE criteria) [20, 22, 31-34]. Figure 1 displays the results of the comparative studies with the ratio of failure between cementless and cemented cups. A ratio of more than one occurred in two studies $[20,35]$ and indicated a worse outcome for the cementless cup. The overall failure rate ratio for the cup was 0.6 (95\% CI: 0.14-2.60), In the study by Glusevicz et al. [35], the failure rate of cementless cups was higher compared to the cemented cups but low compared to the NICE criteria (0.5, see Table 2). This result was not judged as poor. Figure 2 displays the results of the case series. The failure rates in case series without control group were compared to the NICE criteria (failure rate/1). The overall failure rate for the cup was 0.97 (95\% CI: 0.50-1.88).

The results of the four studies based on national arthroplasty registries are summarized in Table 3. In the Finnish Arthroplasty Register, the results of press-fit porous coated cups after 10 years in RA equaled the results of cemented cups in RA in patients younger than 55 years [36]. Smooth threaded cups performed poorly. In a separate report based on the Finnish registry on patients older than 55 years, uncemented cups performed better than cemented ones [37]. Poorly performing implants were excluded from the analysis. In the Swedish register, commonly used cementless cups perform better than commonly used cemented cups in the general population [38]. Sub-analysis for RA was not performed. In the Danish registry, the cumulative risk for revision for aseptic loosening after 14 years was slightly higher for RA than for osteoarthritis (OA) [39]. Sub-analysis for cementless THA was not performed.

Femoral component outcome

Femoral fractures (Table 2): nine studies reported femoral fractures. All reported fractures could be classified as type A according to the Vancouver classification [40], i.e., avulsions of the tip of the trochanter or calcar fissures. In all reported cases, conservative treatment or intra-operative direct fixation was performed, and none caused failure of the implant. 


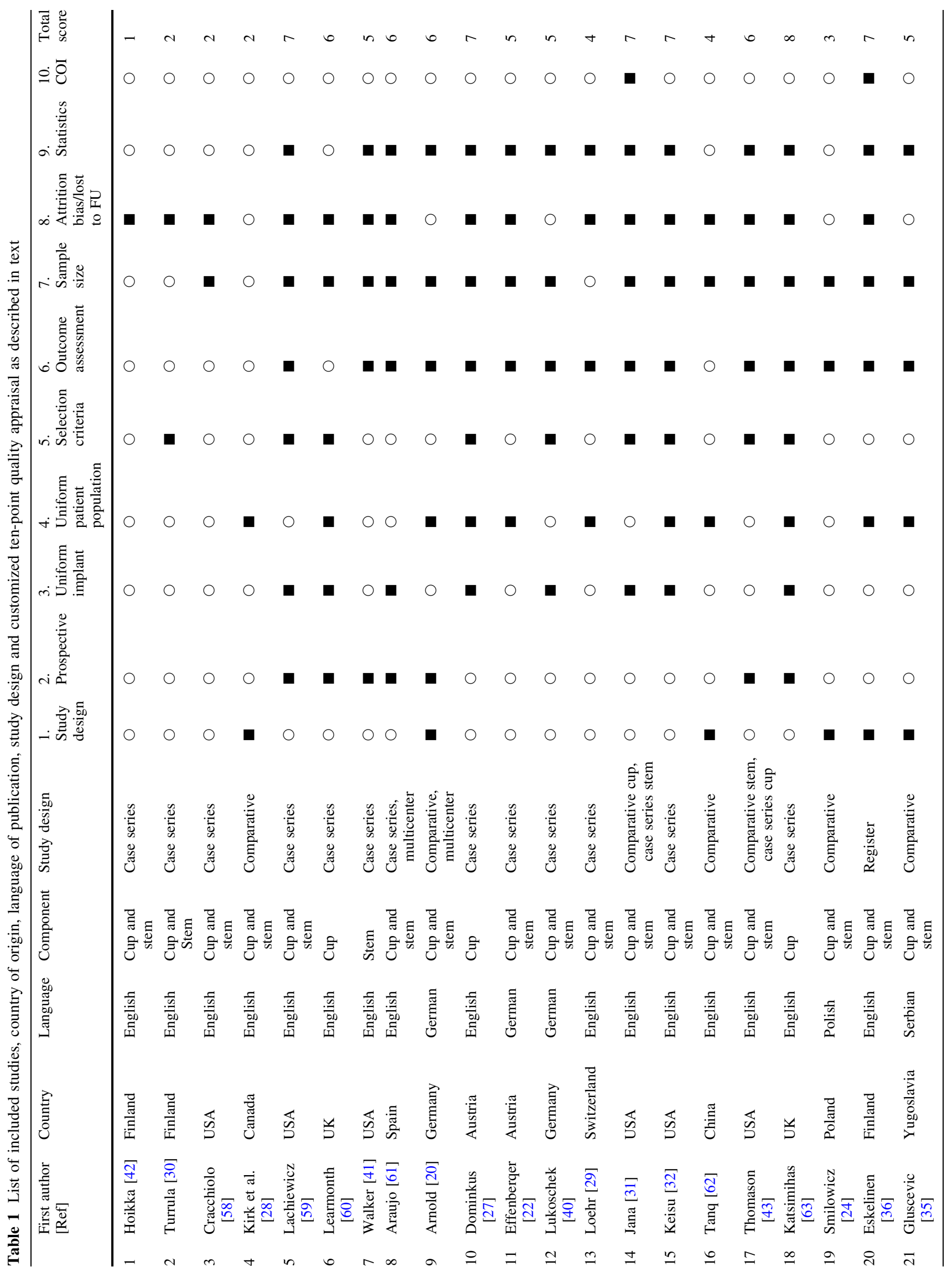




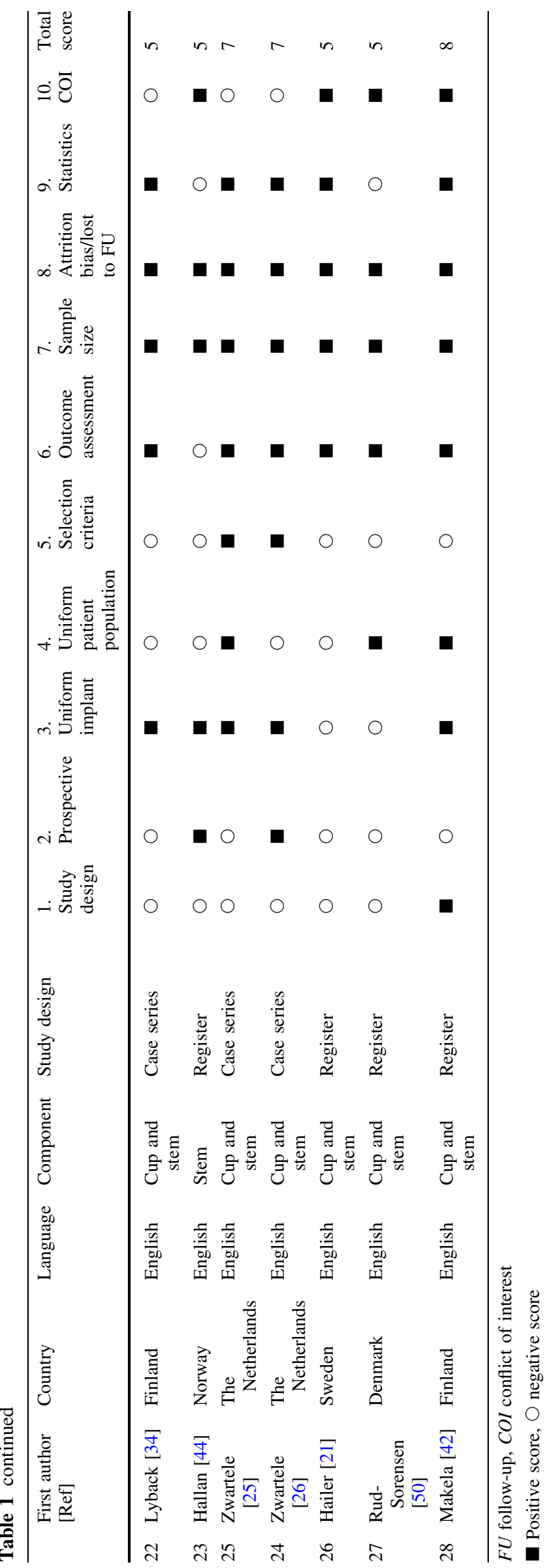

Subsidence (Table 2): ten studies reported subsidence. In the study by Smilowicz et al. [24], the subsidence rate was as high as $80 \%$. Despite this high subsidence rate, only 5 out of the 56 subsided stems were found loose after a mean follow-up of 14 years, resulting in a failure rate of 0.3 . In the other nine studies, only one stem was found loose due to aseptic loosening [41].

Early loosening (Table 2): early aseptic loosening was reported once [42].

Aseptic loosening (Table 2; Figs. 3, 4): Table 2 displays the failure rates per 100 years of 'hips at risk' compared to the NICE criteria. Two studies reported increased failure rates [42, 43]. In the report by Hoikka et al. [42], failure of one stem led to a failure rate of 2.5 due to the small study population and the short follow-up time. This was not judged as a poor result. Figure 3 displays the results of the comparative studies with the ratio of failure between cementless and cemented stems. A ratio of more than one occurred in two studies [20,43] and indicated a worse outcome of the cementless stem. The overall failure rate ratio (uncemented/cemented) for the stem was 0.71 (95\% CI: 0.06-8.55). In the study by Arnold et al. [20], the failure rate of cementless stems was higher compared to cemented stems, but low compared to the NICE criteria (0.4. See Table 2). This was not judged as a poor result. Figure 4 displays the results of the case series. The failure rates in case series without control group were compared to the NICE criteria (failure rate/1). The overall failure rate for the stem was 0.79 (95\% CI: 0.44-1.41).

Table 4 summarizes the results of the five studies based on national arthroplasty registries. The studies on the Finnish register show better results for cementless stems both in young and in older patients with RA [36, 37]. In the studies on the Norwegian [44] and Swedish [38] registries, cementless stems performed well in the general population irrespective of the diagnosis. Sub-analysis for RA was not performed. In the Danish registry, the cumulative risk for revision for aseptic loosening after 14 years was slightly higher for OA than for RA [39]. Sub-analysis for cementless THA was not performed.

\section{Discussion}

Compromised biomechanical properties of rheumatic bone, caused by inflammatory diseases and medication, are potential risk factors for a positive end result of THA in RA patients. This leads to many questions with regard to the practice of implanting cementless components in rheumatic bone. In the last three decades, several studies have been published on cementless THA in RA patients. The results of these articles were assessed to gain insight into the rates of intra-operative, peri-prosthetic fractures and early 


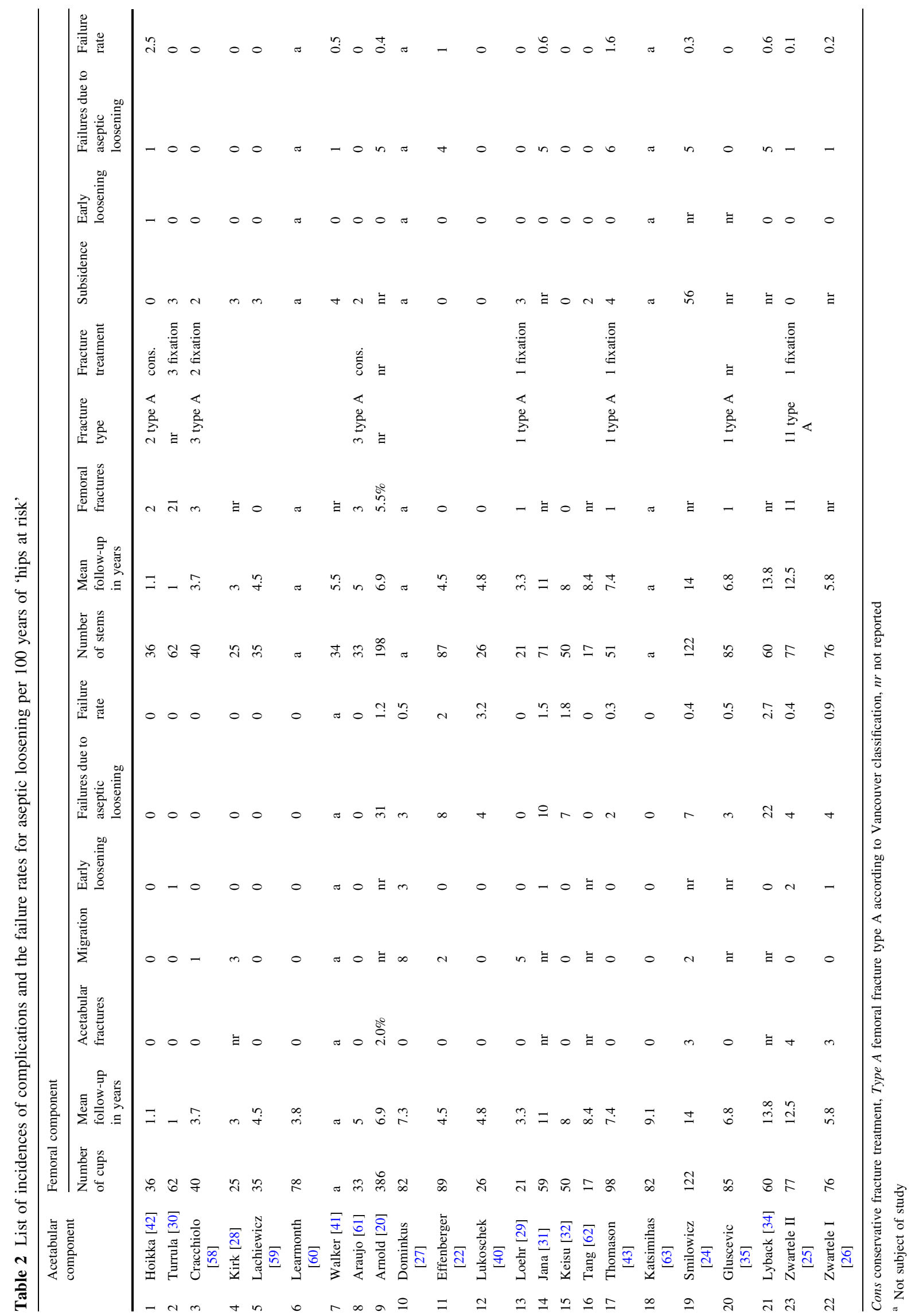




\section{Comparative studies cup}

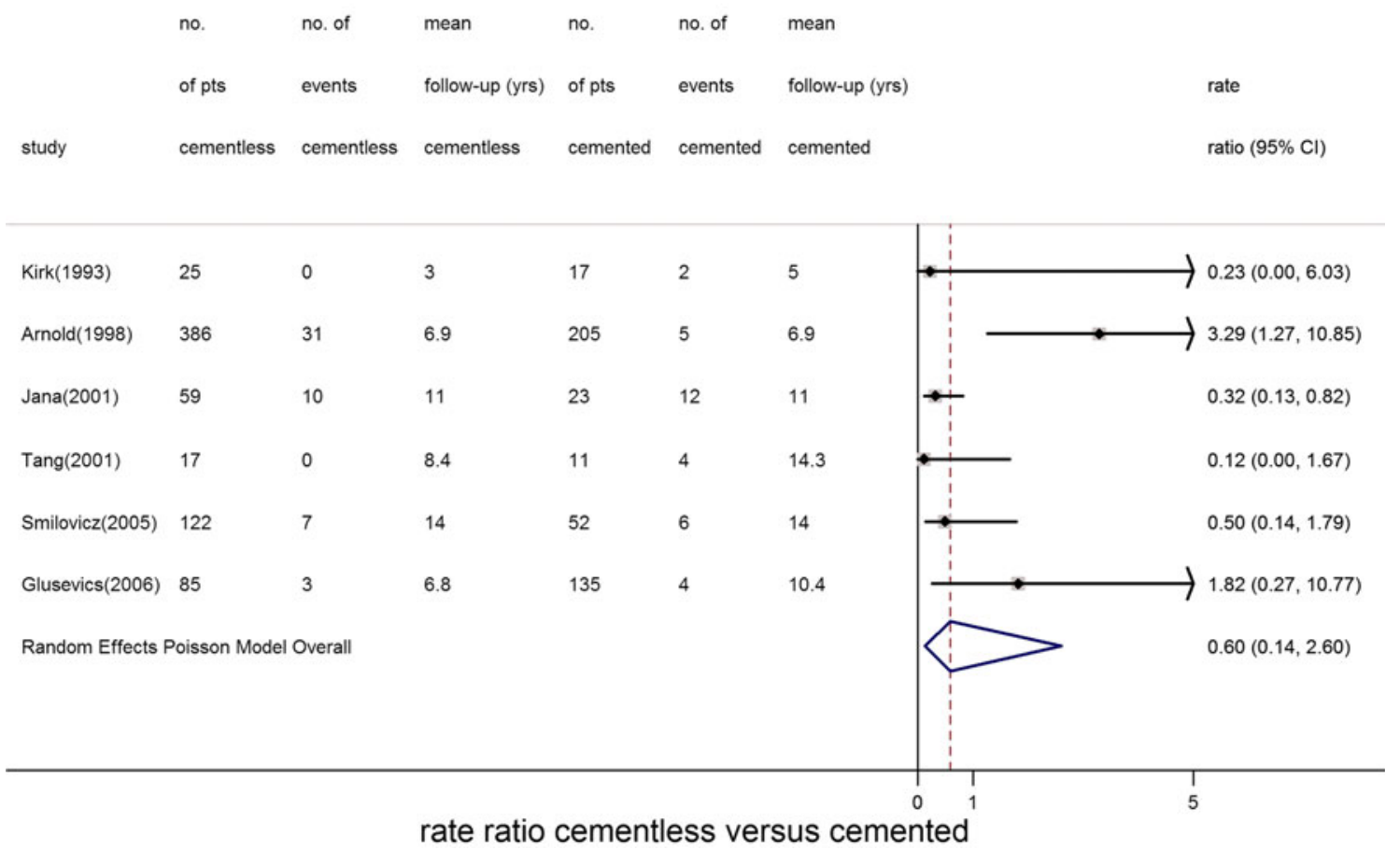

Fig. 1 Comparative studies of cup. Failure rate of cementless cups compared to cemented cups. A ratio of 1 means no difference between the groups, more than 1 means higher failure rate for

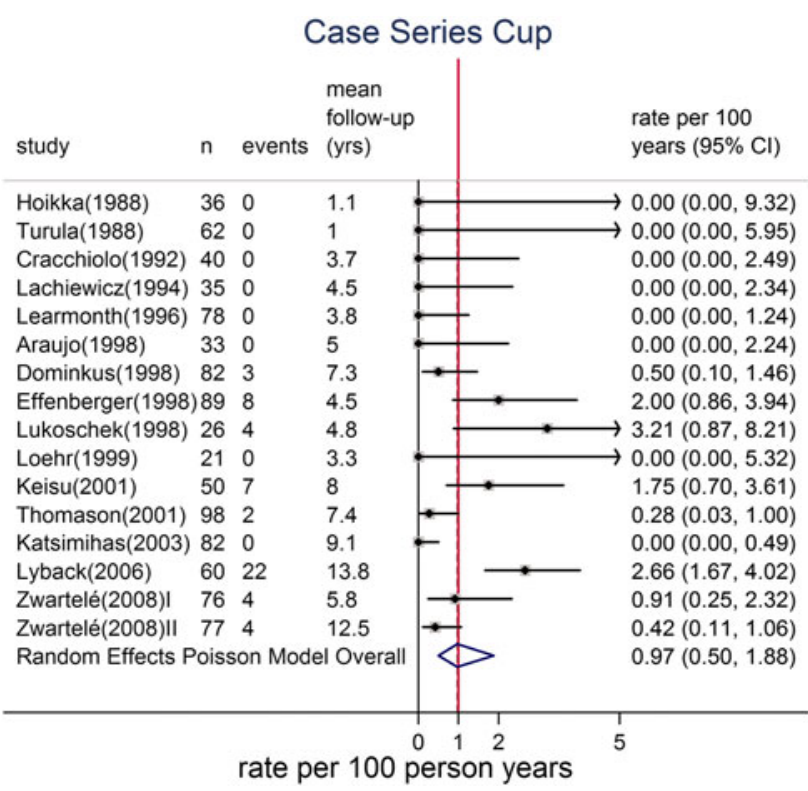

Fig. 2 Case series of cup. Failure rate of cementless cups in relation to the NICE criteria. A ratio of more than 1 means a higher rate of failure than the minimal NICE criteria

complications caused by insufficient initial stability or insufficient osseous integration. The results show that cementless cups are rarely associated with mechanical cementless cups and vice versa. Random effects Poisson model calculated overall as described in the text

complications, while cementless stems result in an increased risk of intra-operative, peri-prosthetic proximal femoral fractures and subsidence. Despite these complications, no well-documented evidence was found that established that cementless components were associated with increased rates of aseptic loosening in RA patients. These findings suggest that initial implant stability and osseous integration are sufficient, despite the altered biomechanical properties of the rheumatic bone.

\section{Validity of data}

This review was conducted as transparently as possible according to a methodology described by several authors [7, 8, 10, 45-47]. Many instruments have been developed for assessing the methodological quality of non-randomized studies [48]. The Newcastle-Ottawa Scale [49] is recommended in the Cochrane Handbook for systematic reviews of interventions [50], but in this specific situation this scale did not lead to a transparent and simple quality appraisal. Our customized list is based on ten items used in other instruments, but simplified to enable a quality appraisal and not a quantified appraisal. Of the 28 studies, 15 had less than six positive scored items, and only 2 studies scored more than seven positive items. Upon 
Table 3 Summaries of the results of the studies based on national arthroplasty registries for acetabular and femoral components, respectively

\begin{tabular}{|c|c|c|c|c|c|c|}
\hline Source & Study design & $\begin{array}{l}\text { Mean } \\
\text { FU } \\
\text { in } \\
\text { years }\end{array}$ & $\begin{array}{l}\text { Diagnosis } \\
\text { and design }\end{array}$ & $\begin{array}{l}\text { Number } \\
\text { of } \\
\text { implants }\end{array}$ & Results & \\
\hline \multirow[t]{4}{*}{$\begin{array}{l}\text { Eskelinen } \\
\text { [36] } \\
\text { Finland }\end{array}$} & \multirow[t]{4}{*}{$\begin{array}{l}\text { Comparison between uncemented and } \\
\text { cemented cups in RA patients } \\
\text { younger than } 55 \text { years }\end{array}$} & & & 2,557 & $\begin{array}{l}\text { Survival at } 10 \text { years with aseptic } \\
\text { loosening as end point }\end{array}$ & $\begin{array}{l}\text { Risk ratio for } \\
\text { revision for } \\
\text { aseptic } \\
\text { loosening }\end{array}$ \\
\hline & & 8.5 & $\begin{array}{l}\text { RA: UC } \\
\text { (PPU) }\end{array}$ & 770 & $92 \%$ (95\% CI:89-94) & $\begin{array}{l}1.0 \text { (95\% CI: } \\
0.8-1.4)\end{array}$ \\
\hline & & 10.9 & $\begin{array}{l}\text { RA: UC } \\
\text { (SU) }\end{array}$ & 317 & 74\% (95\% CI:68-79) & $\begin{array}{l}2.7 \text { (95\% CI: } \\
2.1-3.5)\end{array}$ \\
\hline & & 12.3 & RA: CE & 885 & 91\% (95\% CI:89-94) & 1.0 \\
\hline \multirow[t]{3}{*}{$\begin{array}{l}\text { Hailer [38] } \\
\text { Sweden }\end{array}$} & \multirow[t]{3}{*}{$\begin{array}{l}\text { Comparison between uncemented and } \\
\text { cemented cups in the general } \\
\text { population. No differentiation for } \\
\text { fixation method within the } 5397 \\
\text { RA patients. }\end{array}$} & & & 170,413 & & $\begin{array}{l}\text { Risk ratio for } \\
\text { revision for } \\
\text { aseptic } \\
\text { loosening of } \\
\text { five } \\
\text { most common } \\
\text { uncemented } \\
\text { and } \\
\text { cemented cups }\end{array}$ \\
\hline & & 3.2 & $\begin{array}{l}\text { OA + RA: } \\
\text { UC }\end{array}$ & $\mathrm{nr}$ & $\mathrm{nr}$ & $\begin{array}{l}0.5 \text { (95\% CI: } \\
0.3-0.8)\end{array}$ \\
\hline & & 5.8 & $\begin{array}{l}\mathrm{OA}+\mathrm{RA}: \\
\mathrm{CE}\end{array}$ & $\mathrm{nr}$ & $\mathrm{nr}$ & 1.0 \\
\hline \multirow{5}{*}{$\begin{array}{l}\text { Rud- } \\
\text { Sorensen } \\
\text { [39] } \\
\text { Denmark }\end{array}$} & \multirow[t]{5}{*}{$\begin{array}{l}\text { Comparison between RA and OA } \\
\text { patients. No differentiation for } \\
\text { uncemented or cemented cups }\end{array}$} & 5.9 & & & $\begin{array}{l}\text { Cumulative risk on } \\
\text { revision for aseptic } \\
\text { loosening at } 14 \text { years }\end{array}$ & \\
\hline & & & $\begin{array}{l}\text { OA: } \\
\quad \mathrm{UC}+\mathrm{CE}\end{array}$ & 64,858 & $\begin{array}{l}4.6 \% \text { (95\% CI: } \\
\quad 4.0-5.1\end{array}$ & \\
\hline & & & $\begin{array}{l}\text { RA: } \\
\text { UC }+ \text { CE }\end{array}$ & 1,661 & $\begin{array}{l}5.7 \% \text { (95\% CI: } \\
3.7-8.8)\end{array}$ & \\
\hline & & & RA: UC & 878 & $\mathrm{nr}$ & \\
\hline & & & RA: CE & 783 & $\mathrm{nr}$ & \\
\hline \multirow[t]{3}{*}{$\begin{array}{l}\text { Makela } \\
\text { [37] } \\
\text { Finland }\end{array}$} & \multirow[t]{3}{*}{$\begin{array}{l}\text { Comparison between uncemented and } \\
\text { cemented cups in RA patients } 55 \text { years } \\
\text { and older. Exclusion of implants with } \\
\text { well-documented poor results }\end{array}$} & & & & $\begin{array}{l}\text { Survival at } 10 \text { years with aseptic } \\
\text { loosening as end } \\
\text { point }\end{array}$ & $\begin{array}{l}\text { Risk ratio for } \\
\text { revision for } \\
\text { aseptic } \\
\text { loosening }\end{array}$ \\
\hline & & 8.2 & RA: UC & 579 & 97\% (95\% CI: 95-99) & $\begin{array}{l}0.57 \text { (95\% CI: } \\
0.36-0.92)\end{array}$ \\
\hline & & 7.7 & RA: CE & 3,440 & 94\% (95\% CI: 93-95) & 1.0 \\
\hline
\end{tabular}

$O A$ osteoarthritis, $R A$ rheumatoid arthritis, $U C$ uncemented cup, $C E$ cemented cup, $P P U$ press-fit porous coated cup, $S U$ smooth threaded cup, $C I$ confidence interval

analysis of the results of the quality appraisal, it is obvious that the quality of most studies is poor and that the results of the studies are potentially subject to all kinds of bias. Despite these limitations-and the great variation in the included studies with respect to methodology, patient population, implants used, year and location of conduct, and quality-the results are quite uniform, as only a few, mostly explainable, deviations were found.
Interpretation of acetabular component outcome

Acetabular fractures: intra-operative peri-prosthetic acetabular fractures are rare, especially when press-fit cups are used. All fractures were treated conservatively and none caused implant failure.

Migration: six studies report on migrated cups, three of them in more than $10 \%$ of the cups. Migration is said to be a predictor of component failure [51] On the other hand, 
Comparative studies stem

$\begin{array}{llllllll} & \text { no. } & \text { no. of } & \text { mean } & \text { no. } & \text { no. of } & \text { mean } & \\ & \text { of pts } & \text { events } & \text { follow-up (yrs) } & \text { of pts } & \text { events } & \text { follow-up (yrs) } & \log \text { rate } \\ \text { study } & \text { cementless } & \text { cementless } & \text { cementless } & \text { cemented } & \text { cemented } & \text { cemented } & \text { ratio }(95 \% \mathrm{Cl})\end{array}$

\begin{tabular}{|c|c|c|c|c|c|c|c|}
\hline Kirk (1993) & 25 & 0 & 3 & 17 & 2 & 5 & $0.23(0.01,6.03)$ \\
\hline Arnold (1998) & 198 & 5 & 6.9 & 393 & 6 & 6.9 & $1.65(0.40,6.50)$ \\
\hline Tang (2001) & 17 & 0 & 8.4 & 11 & 1 & 14.3 & $0.37(0.01,42.96)$ \\
\hline Thomason (2001) & 51 & 6 & 7.4 & 47 & 0 & 7.4 & $11.98(1.09,100.00)$ \\
\hline Smilovics (2005) & 122 & 5 & 14 & 52 & 6 & 14 & $0.36(0.09,1.40)$ \\
\hline Glusevic (2007) & 85 & 0 & 6.8 & 135 & 1 & 10.4 & $0.81(0.01,94.73)$ \\
\hline \multicolumn{7}{|c|}{ Random Effects Poisson Model Exact Overall } & $0.71(0.06,8.55)$ \\
\hline
\end{tabular}

Fig. 3 Comparative studies of stem. Failure rate of cementless stems compared to cemented stems. A ratio of 1 means no difference between the groups, more than 1 means higher failure rate for

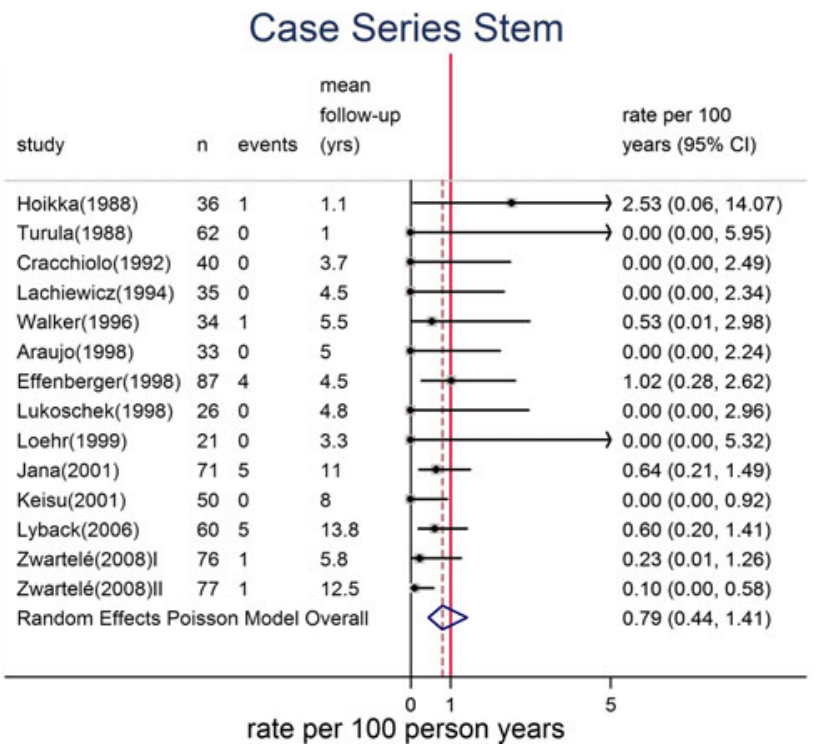

Fig. 4 Case series of stem. Failure rate of cementless stems in relation to the NICE criteria. A rate of more than 1 means a higher rate of failure than the minimal NICE criteria

limited early migration could be a seating effect of cementless cups without having consequences on the outcome. Due to the limited follow-up time, it is not possible to distinguish between these two mechanisms. cementless stems and vice versa. Random effects Poisson model calculated overall as described in the text

Early aseptic loosening: early aseptic loosening is rare. Increased rates of early aseptic loosening was reported twice, both in studies with the threaded Zweymuller cup $[25,27]$. The long-term results of both studies were excellent.

Aseptic loosening: six studies showed poor results of cementless cups in RA, one comparative study [20] and five case series [22, 31-34]. In five of these studies with poor result, the smooth threaded cup design was blamed. High failure rates of these designs are confirmed by several studies with OA patients [52-54]. In the sixth study with poor results [32], the hemispherical cup design was blamed, the cause being wear of the polyethylene caused by a thin liner as described earlier in OA patients [55]. The Finnish register accounted for these poor performing components and made sub-analysis for different types of designs. They concluded that in young patients with RA, the results of the cementless cups were as good as the results of cemented ones [36], while in older patients the results of cementless cups were better than those of cemented cups [37].

Interpretation of femoral component outcome

Femoral fractures: a majority of the studies reported intraoperative, peri-prosthetic fractures. All fractures were type 
Table 4 Summaries of the results of the studies based on national arthroplasty registries for acetabular and femoral components, respectively

\begin{tabular}{|c|c|c|c|c|c|c|}
\hline Source & Study design & $\begin{array}{l}\text { Mean } \\
\text { FU in } \\
\text { years }\end{array}$ & $\begin{array}{l}\text { Diagnosis and } \\
\text { design }\end{array}$ & $\begin{array}{l}\text { Number } \\
\text { of } \\
\text { implants }\end{array}$ & Results & \\
\hline \multirow[t]{4}{*}{$\begin{array}{l}\text { Eskelinen } \\
\text { [36] } \\
\text { Finland }\end{array}$} & \multirow[t]{4}{*}{$\begin{array}{l}\text { Comparison between uncemented and } \\
\text { cemented stems in RA patients } \\
\text { younger than } 55 \text { years }\end{array}$} & & & 2,557 & $\begin{array}{l}\text { Survival at } 10 \text { years } \\
\text { with aseptic } \\
\text { loosening as end } \\
\text { point }\end{array}$ & $\begin{array}{l}\text { Risk ratio for revision for } \\
\text { aseptic loosening }\end{array}$ \\
\hline & & 8 & $\begin{array}{l}\text { RA: UC } \\
\text { (PPU) }\end{array}$ & 913 & 97\% (95\% CI:96-99) & 0.4 (95\% CI:0.3-0.6) \\
\hline & & 8.5 & RA: UC (UU) & 230 & $86 \%$ (95\% CI:80-91) & 1.7 (95\% CI:1.2-2.5) \\
\hline & & 8.5 & RA: CE & 878 & 90\% (95\% CI:88-92) & 1.0 \\
\hline \multirow[t]{2}{*}{$\begin{array}{c}\text { Hallan [44] } \\
\text { Norway }\end{array}$} & \multirow[t]{2}{*}{$\begin{array}{l}\text { Uncemented stems in the general } \\
\text { population. No differentiation } \\
\text { between population and the } 5.5 \% \\
\text { RA patients }\end{array}$} & & & & $\begin{array}{l}\text { Survival at } 10 \text { years } \\
\text { with aseptic } \\
\text { loosening as end } \\
\text { point (the } 8 \text { most } \\
\text { used stems) }\end{array}$ & $\begin{array}{l}\text { Risk ratio for revision for } \\
\text { aseptic loosening }\end{array}$ \\
\hline & & & $\mathrm{OA}+\mathrm{RA}: \mathrm{UC}$ & 9,757 & 96 to $100 \%$ & $\begin{array}{l}\text { Diagnosis did not influence } \\
\text { the results }\end{array}$ \\
\hline \multirow[t]{3}{*}{$\begin{array}{l}\text { Hailer [38] } \\
\text { Sweden }\end{array}$} & \multirow[t]{3}{*}{$\begin{array}{l}\text { Comparison between uncemented and } \\
\text { cemented stems in the general } \\
\text { population. No differentiation for } \\
\text { fixation method within the } 5397 \text { RA } \\
\text { patients }\end{array}$} & & & 170,413 & & $\begin{array}{l}\text { Risk ratio for revision for } \\
\text { aseptic loosening of the } \\
\text { five most common } \\
\text { uncemented and } \\
\text { cemented stems }\end{array}$ \\
\hline & & 5.1 & $\begin{array}{l}\text { OA + RA: } \\
\text { UC }\end{array}$ & $\mathrm{nr}$ & $\mathrm{nr}$ & 0.3 (95\% CI:0.2-0.4) \\
\hline & & 5.8 & $\begin{array}{l}\mathrm{OA}+\mathrm{RA}: \\
\mathrm{CE}\end{array}$ & $\mathrm{nr}$ & $\mathrm{nr}$ & 1.0 \\
\hline \multirow[t]{5}{*}{$\begin{array}{l}\text { Rud- } \\
\text { Sorensen } \\
\text { [39] } \\
\text { Denmark }\end{array}$} & \multirow[t]{5}{*}{$\begin{array}{l}\text { Comparison between RA and OA } \\
\text { patients. No differentiation for } \\
\text { uncemented or cemented stems }\end{array}$} & 5.9 & & & $\begin{array}{l}\text { Cumulative risk on } \\
\text { revision for aseptic } \\
\text { loosening at } 14 \\
\text { years }\end{array}$ & \\
\hline & & & $\begin{array}{l}\text { OA: } \\
\quad \mathrm{UC}+\mathrm{CE}\end{array}$ & 64,858 & $\begin{array}{l}4.3 \%(95 \% \\
\text { CI:3.8-4.8) }\end{array}$ & \\
\hline & & & $\begin{array}{l}\text { RA: } \\
\text { UC }+ \text { CE }\end{array}$ & 1,661 & $\begin{array}{l}3.2 \%(95 \% \\
\text { CI: } 1.8-5.9)\end{array}$ & \\
\hline & & & RA: UC & 446 & $\mathrm{nr}$ & \\
\hline & & & RA: CE & 1,215 & $\mathrm{nr}$ & \\
\hline \multirow[t]{4}{*}{$\begin{array}{l}\text { Makela } \\
\text { [37] } \\
\text { Finland }\end{array}$} & \multirow{4}{*}{$\begin{array}{l}\text { Comparison between uncemented and } \\
\text { cemented THA in RA patients } \\
55 \text { years and older. Exclusion of } \\
\text { implants with well-documented } \\
\text { poor results }\end{array}$} & & & & $\begin{array}{l}\text { Survival at } 10 \text { years } \\
\text { with aseptic } \\
\text { loosening as end } \\
\text { point }\end{array}$ & $\begin{array}{l}\text { Risk ratio for revision for } \\
\text { aseptic loosening }\end{array}$ \\
\hline & & 8.2 & RA: UC & 579 & $\begin{array}{l}98 \%(95 \% \\
\text { CI: } 97-100)\end{array}$ & 0.39 (95\% CI:0.20-0.76) \\
\hline & & 7.7 & RA: CE (LT) & 1,535 & $96 \%$ (95\% CI:94-97) & 1.0 \\
\hline & & & RA: CE (CB) & 1,905 & 92\% (95\% CI:90-94) & 1.85 (95\% CI:1.34-2.55) \\
\hline
\end{tabular}

$O A$ osteoarthritis, $R A$ rheumatoid arthritis, $U C$ uncemented stem, $C E$ cemented stem, $P P U$ proximally porous coated stem, $U U$ uncoated stem, $C I$ confidence interval, $L T$ loaded taper (cemented stem design allowing subsidence), $C B$ composite beam (cemented stem design not intended to subside)

A fractures and could be treated conservatively or with cerclage wires. There were no reports of late peri-prosthetic fractures caused by a fall or major trauma. These latter fractures (when classified as type B or C) are known to be a major mode of failure of uncemented stems [38, 56, 57]. Irrespective of the diagnosis, implantation of cementless stems seems to be associated with an increased risk of periprosthetic fractures.

Subsidence: subsidence is reported frequently in a majority of the studies, but does not seem to be a predictor of implant failure, as the failure rates of cementless stems were low even in studies with high subsidence rates. 
Early aseptic loosening: early aseptic loosening was rarely reported.

Aseptic loosening: poor results due to aseptic loosening of the stem were reported in one study [43]. The authors blamed this high failure rate on the first-generation cementless stem design. All other studies reported good results of the cementless stems in RA.

\section{Conclusions}

Despite the poor quality of most studies, the results were quite uniform, as only a few, mostly explainable, deviations were found. Cementless cups are rarely associated with mechanical complications. Cementless stems have substantial risks on intra-operative, peri-prosthetic proximal femoral fractures, and subsidence. No evidence, which established that well-documented cementless components were associated with increased rates of aseptic loosening in RA patients, was found. These findings suggest that initial implant stability and osseous integration are sufficient despite the altered biomechanical properties of the rheumatic bone. The results justify the use of cementless THA in RA patients. Whether this conclusion will last in the long run has to be confirmed by awaited long-term studies.

Acknowledgments The authors wish to thank Mr Vladan Ilic and Mr Piotr Stolarczyk for their translation of the Serbian and the Polish articles, respectively.

Open Access This article is distributed under the terms of the Creative Commons Attribution Noncommercial License which permits any noncommercial use, distribution, and reproduction in any medium, provided the original author(s) and source are credited.

\section{References}

1. Åkesson K, Önsten I, Obrant KJ (1994) Periarticular bone in rheumatoid arthritis versus arthrosis. Acta Orthop Scand 65:135138

2. Bogoch ER, Moran EL (1999) Bone abnormalities in the surgical treatment of patients with rheumatoid arthritis. Clin Orthop 366:8-21

3. Oettmeier R, Babisch J (1992) Osteologic standardization of human coxarthrosis using histomorphometry and its relevance for hip alloarthroplasty. Pathol Res Pract 188:620-624

4. Trancik T, Mills W, Vinson N (1989) The effect of indomethacin, aspirin, and ibuprofen on bone ingrowth into a porous-coated implant. Clin Orthop 249:113-121

5. Wheeler DL, vander Griend RA, Wronski TJ et al (1995) The short- and long-term effects of methotrexate on the rat skeleton. Bone 16:215-216

6. Nice: National Institute of Clinical Excellence (2000). Guidance on the selection of prostheses for primary total hip replacement. London. http://guidance.nice.org.uk

7. Stroup D, Berlin J, Mothon S et al (2000) Meta-analysis of observational studies in epidemiology. JAMA 283:2008-2012
8. von Elm E, Altman D, Egger M et al (2007) The strengthening the reporting of observational studies in epidemiology (STROBE) statement: guidelines for reporting observational studies. Plosmedicine 4(10):e296

9. Sanderson S, Tatt I, Higgins J (2007) Tools for assessing quality and susceptibility to bias in observational studies in epidemiology: a systematic review and annotated bibliography. Int J Epidemiol 36:666-766

10. Simunovic N, Sprague S, Bhandari M (2009) Methodological issues in systemic reviews and meta-analyses of observational studies in orthopaedic research. J Bone Jt Surg Am 91(suppl 3):87-94

11. Zlowodzki M, Poolman R, Kerkhoffs G et al (2007) How to interpret a meta-analysis and judge its value as a guide for clinical practice. Acta Orthop 78:598-609

12. Stijnen T, Hamza TH and Özdemir P (2010) Tutorial in biostatistics: random effects meta-analysis of event outcome in the framework of the generalized linear mixed model with applications in sparse data. Stat Med. doi:10.1002/sim.4040

13. Waddell J (1993) Cemented and uncemented hip implants in patients with rheumatoid arthritis. Can J Surg 3:199

14. Kumar M, Swann M (1998) Uncemented total hip arthroplasty in young patients with juvenile chronic arthritis. Ann R Coll Surg Engl 80:203-209

15. Haber D, Goodman S (1998) Total hip arthroplasty in juvenile chronic arthritis. J Arthroplast 13:259-265

16. von Dustmann H, Godolias G (1990) Zementfrei implantierte Hüftgelenks-Totalendoprothesen nach Zweymüller/Endler und Zweymüller bei Chronischer Polyarthritis. Orthop Praxis 1:25-27

17. Hoos R, Refior H (1987) Frühergebnisse des zementfreien alloarthropastischen Hüftgelenksersatzes bei entzündlich-rheumatischen Erkrankunegen. Akt Rheumatol. 12:57-60

18. Longree P, Gillet, Chaar O et al (1988) Utilisation de la cupule RM non cimentee dans l'arthroplatie par prothese totale des coxites inflammatoires. Acta Orthop Belgica 54:142-147

19. van Raay J, Rozing P (1991) Uncemented bipolar double-cup arthroplasty of the hip in inflammatory arthropathy. J Arthroplast 6:79-88

20. Arnold P, Schüle B, Schroeder-Boersch H et al (1998) Review of the results of the ARO multicenter study. Orthopade 27:324-332

21. Schule B, Schroeder-Boersch H, Arnold P et al (1998) Implantatvesager nach Hüft-TEP-Implantation. Orthopäde 27:341-348

22. Effenberger H, Lassmann S, Hizensauer G et al (1998) Zementfreie Hüftendoprothetik bei Patienten mit rheumatoide Arthritis. Orthopäde 27:354-365

23. Effenberger H, Ramsauer T, Böhm G et al (2001) Successful hip arthroplasty using cementless titanium implants in rheumatoid arthritis. Arch Orthop Tr Surg 122:80-87

24. Smilowicz M, Kowalczewski J (2005) Long-term results after total hip replacement; cemented and cementless in young rheumatic patients. Chirurgia Narzadow Ruchu i Ortopedia Polska 70(5):319-323

25. Zwartele R, Peters A, Brouwers J et al (2008) Long-term results of cementless primary total hip arthroplasty with a threaded cup and a tapered, rectangular titanium stem in rheumatoid arthritis and osteoarthritis. Int Orthop 32:581-587

26. Zwartele R, Olsthoorn P, Pöll R et al (2008) Primary total hip arthroplasty with a flattened press-fit acetabular component in osteoarthritis and inflammatory arthritis: a prospective study on 416 hips with 6 to 10 years follow-up. Arch Orthop Trauma Surg 128:1379-1386

27. Dominkus M, Wanivenhaus A, Morscher M et al (1998) Different cup migration in rheumatoid arthritis and arthrosis. Acta Orthop Scand 69:455-462

28. Kirk P, Rorabeck C, Bourne R et al (1993) Total hip arthroplasty in rheumatoid arthritis: comparison of cemented and uncemented implants. Can J Surg 36:229-232 
29. Loehr J, Munzinger U, Tibesku C (1999) Uncemented total hip arthroplasty in patients with rheumatoid arthritis. Clin Orthop 366:31-38

30. Turula K, Savioja S, Innes A et al (1988) Early results of cementless total hip replacement in inflammatory joint disease. Scand J Rheumat 67:61-63

31. Jana A, Engh C, Lewandowski P et al (2001) Total hip arthroplasty using porous-coated femoral components in patients with rheumatoid arthritis. J Bone Jt Surg Br 83:686-690

32. Keisu K, Orozco F, McCallum J et al (2001) Cementless femoral fixation in the rheumatoid patient undergoing total hip arthroplasty. J Arthroplast 16:415-421

33. Lukoschek M, Simank H, Bocai D (1998) Zemenfreie Hüftendoprothetik bei entzündlich-rheumatischen Erhrankungen. Orthopäde 27:392-395

34. Lybäck C, Lybäck C, Kyrö A et al (2006) A long-term follow-up of 69 Lord total hip arthroplasties in rheumatic disease: a mean follow-up of 14 years. Int Orthop 30:391-394

35. Gluscevic B, Kraljevic B, Jovanovic V et al (2006) Primary total hip arthroplasty in patients with rheumatoid arthritis. Acta chirurgica iugoslavica 53(4):117-120

36. Eskelinen A, Paavolainen P, Helenius I et al (2006) Total hip arthroplasty for rheumatoid arthritis in younger patients. Acta Orthop 77:853-865

37. Mäkelä KT, Eskelinen A, Pulkkinen P et al (2011) Cemented versus cementless total hip replacement in patients fifty-five years of age or older with rheumatoid arthritis. J Bone Jt Surg Am 93:178-186

38. Hailer N, Garellick G, Kärrholm J (2010) Uncemented and cemented primary total hip arthroplasty in the Swedish Hip Arthroplasty Register. Acta Orthop 81:34-41

39. Rud-Sorensen C, Pedersen A, Paaske Johnsen S et al (2010) Survival of primary total hip arthroplasty in rheumatoid arthritis patients. Acta Orthop 81:60-65

40. Duncan CP, Masri BA (1995) Fractures of the femur after hip replacement. Instr Course Lect 44:293

41. Walker K, Kyle R, Gustilo R (1996) Noncemented femoral components in total hip arthroplasty for patients with rheumatoid arthritis. Minn Med 79:27-31

42. Hoikka V, Peltonen J, Kytomaa et al (1988) Early results of cementless total hip replacement in rheumatoid arthritis and related conditions. Scand J Rheumatol 67:56-60

43. Thomason H, Lachiewicz $P$ (2001) The influence of technique on fixation of primary total hip arthroplasty in patients with rheumatoid arthritis. J Arthroplast 16:628-634

44. Hallan G, Lie S, Furnes O et al (2007) Medium- and long-term performance of 11, 516 uncemented primary femoral stems from the Norwegian arthroplasty register. J Bone Jt Surg $\mathrm{Br}$ 89:1574-1580

45. Manchikanti L, Datta S, Smith H et al (2009) Evidence-based medicine, systematic reviews, and guidelines in interventional pain management: part 6 . Systematic reviews and meta-analyses of observational studies. Pain Physician 12:819-850
46. Moher D, Liberati A, Tetzlaff J, Altmann D, Group PRISMA (2009) Preferred reporting items for systematic reviews and metaanalyses: the PRISAM statement. BMJ 339(21):b2535

47. Wright R, Brand R, Dunn W et al (2007) How to write a systematic review. Clin Orthop 455:23-29

48. Deeks J, Dinnes J, D'Amico R, et al., International Stroke Trial Collaborative Group, European Carotid Surgery Trial Collaborative Group (2003) Evaluating non-randomised intervention studies. Health Technol Assess 7(27):iii-x, 1-173

49. Wells G, O'Connell S, Peterson J et al (2008) The NewcastleOttowa Scale (NOS) for assessing the quality of nonrandomized studies in meta-analyses. http://www.ohri.ca/programs/clinical_ epidemiology/oxford.htm (accessed 1 January 2008)

50. Higgins JPT, Green S (2009) Cochrane handbook for systematic reviews, version 5.0.2 The Cochrane Collaboration. http://www. cochrane-handbook.org

51. Krismer M, Stoeckl B, Fisher M et al (1996) Early migration predicts late aseptic failure of hip sockets. J Bone Jt Surg $\mathrm{Br}$ 78:422-426

52. Clarius M, Jung A, Streit M et al (2010) Long-term results of the threaded Mecron cup in primary total hip arthroplasty: a 15-20 year follow-up study. Int Orthop 34:1093-1098

53. Dickob M, Martini T (1996) The cementless PM hip arthroplasty. Four to seven year results. J Bone Jt Surg Br 78:195-199

54. Grant P, Nordsletten L (2004) Total hip arthroplasty with the Lord prosthesis. A long-term follow-up study. J Bone Jt Surg Am 86:2636-2641

55. Hozack W, Rothman R, Eng K et al (1996) Primary cementless hip arthroplasty with a titanium plasma sprayed prosthesis. Clin Orthop 333:217-225

56. Laurer HL, Wutzler S, Possner S et al (2011) Outcome after operative treatment of Vancouver type B1 and C peri-prosthetic femoral fractures: open reduction and internal fixation versus revision arthroplasty. Arch Orthop Trauma Surg. doi:10.1007/ s00402-011-1272-y [Epub ahead of print]

57. Streit MR, Merle C, Clarius M et al (2011) Late peri-prosthetic femoral fracture as a major mode of failure in uncemented primary hip replacement. J Bone Jt Surg Br 93:178-183

58. Cracchiolo A, Severt R, Moreland J (1992) Uncemented total hip arthroplasty in rheumatoid arthritis diseases. Clin Orthop 277:166-174

59. Lachiewicz P (1994) Porous-coated total hip arthroplasty in rheumatoid arthritis. J Arthroplast 91:9-15

60. Learmonth I, Sarangi P, Lee M et al (1996) Cementless replacement to the acetabulum at total hip arthroplasty in rheumatoid arthritis. J Orthop Rheumatol 9:33-36

61. Araujo J, Gonzalez J, Tonino A, International ABG study group (1998) Rheumatoid arthritis and hydroxyapatite-coated hip prostheses. J Arthroplast 13(6):660

62. Tang W, Chiu K (2001) Primary total hip arthroplasty in patients with rheumatoid arthritis. Int Orthop 25:13-16

63. Katsimihas M, Taylor A, Lee M et al (2003) Cementless acetabular replacement in patients with rheumatoid arthritis. $\mathrm{J} \mathrm{Ar}$ throplast 18:16-22 